\title{
Communicating trust and trusting science communication - some critical remarks
}

\section{Alan Irwin and Maja Horst}

\begin{abstract}
Written in response to a previous article by Weingart and Guenther [2016] in JCOM, this letter aims to open up some critical issues concerning the 'new ecology of communication'. It is argued that this evolving ecology needs to be openly explored without looking back to a previous idyll of 'un-tainted' science.
\end{abstract}

We are very grateful to Peter Weingart and Lars Guenther for addressing the relationship between science communication and public trust - and especially for setting this within what they call the 'new ecology of communication'. As they rightly suggest, science communication is a diverse business encompassing many different actors. It follows that we cannot hope to understand the dynamics of trust without taking full account of science communication's developing character. As we write in the wake of Brexit and with an eye on the 2016 presidential elections in the United States, it does seem that trust in experts is in short supply with many commentators suggesting that 'facts' are losing out in their battle with 'opinion'. As Weingart and Guenther express their related argument, the truth through science is being degraded by PR and actors whose 'communication is tainted by special interests' [Weingart and Guenther, 2016, abstract]. Our comments below will suggest that, whilst we recognize the underlying questions and concerns, we do have a rather different perspective on some of the key issues and especially on the overall conceptual framework employed by Weingart and Guenther.

Certainly, these questions of the developing nature of science communication, of its multiple meanings, and of the dynamics of public trust are hugely important. In general, we draw great inspiration from Weingart and Guenther's account.

However, we also read their article as, at least at times, deliberately provocative in character. From our perspective, one can legitimately raise these issues without needing to summon up a Golden Age of public trust in science. It is hard not to read a certain deliberate irony in the expression 'idyllic state of affairs' to describe nineteenth century science communication. Equally, the suggestion that science is (always?) 'oriented to the common good and transcends political ideologies and/or economic interests' seems to us like an obvious over-generalisation. Reflecting upon previous research in science and technology studies, it is difficult to accept that science is by its very nature 'the ultimate reference ... when reliable 
knowledge is at stake'. Instead, we would support the later statement in the paper that 'trust varies from one source to another' and that it is contextually assessed.

There is also the suggestion here that science communication is basically a matter of providing information and initiating critical thinking 'on the part of the recipient' (only?). This jars with our understanding of communication as contextual sense-making - and also risks suggesting a decidedly one-way communication form. Surely even the most 'tainted' PR company has to take full notice of its specific audiences and their likely judgements and responses if it is in any way to succeed? Just to return the authors' provocation, we would suggest that, rather than science communication simply being tainted by PR, scientists and science communicators might actually have something to learn about audience segmentation and the need to respond to, as well as 'push', information. Put differently, is 'persuasive communication' necessarily a bad thing?

We share with Weingart and Guenther a sceptical perspective on the growth of PR in this context. But this does not mean that we cannot draw valuable lessons from its perspectives and mode of operation - particularly when these are thoughtfully expressed as here by the long-time science PR practitioner Rick Borchelt (writing with Kristian Nielsen), who suggests that we should:
'view PR in a scientific organisation as managing the trust portfolio - both for the organisation and for the scientific enterprise more generally, and as a unifying concept for future scholarship. The trust portfolio has several components: accountability, competence, credibility, dependability, integrity, legitimacy and productivity. Managing the trust portfolio means planning and managing a wide variety of strategic communication programmes building diverse relationships between science and different publics.' [Borchelt and Nielsen, 2014, p. 59]

Such an account paints a rather different view of the practice of science PR than the one presented in the discussion paper. So whilst we agree that one should generally take a very cautious approach to the practice of PR in the context of science, we would not say that PR is intrinsically misguided or unethical in principle. Rather, it is one form of communication within the ecology of science communication and should be studied empirically and openly as such - both in terms of its practices and consequences.

Drawing upon several of the points made by Peter Weingart and Lars Guenther, but also our own knowledge and experience, our suggestion is that the following elements are especially important in grappling with the relationship between science communication and public trust. Since this is intended as a short reaction rather than a full paper [but see Davies and Horst, 2016; Horst, Davies and Irwin, forthcoming], we will necessarily be brief in our comments.

First of all, and here we are broadly in agreement with Weingart and Guenther, science communication involves a diversity of actors and covers many activities. We will leave aside the question of whether this is a new development [see for example Shapin and Schaffer, 1985]. From our perspective, science communication extends from the dissemination efforts of high-profile scientists through what we would see as organizational communication around science and on to the larger 
media, science fiction and the activities of bloggers and journalists. For us, this ecology of communication practices cannot be encompassed by a one-dimensional distinction between PR and enlightenment - or between instrumental and truth-seeking communication. Furthermore, we find that very often scientists are not simply speaking on behalf of science, but also 'branding' their own research fields and sometimes also their research groups [Horst, 2013].

Secondly, and following from the above point, at least when it comes to science communication, it seems that there is no clear line between technical 'information' and institutionally- or personally-driven goals, interests and messages. Science communication is indeed about many things, and these will involve 'information' in different ways and forms just as they also always involve sense-making about science, scientists and scientific organizations. When the high-profile Danish scientist, Eske Willerslev, explains how his research brings us a new and important understanding of pre-historic mass migrations, he is both contributing to the general enlightenment of his audiences and also branding himself as a 'public scientist' [see e.g. Zimmer, 2016]. We see no inherent shame or fault in this and we have no reason to question his enthusiasm to engage the audience with his scientific knowledge. At the same time, we view his actions as clearly building up a certain level of fame, societal reputation and celebrity, with presumably instrumental benefits.

Thirdly, and referring specifically to the relationship between science and industry, we find it increasingly difficult to maintain a distinction between what is referred to here as 'science proper' and 'scientists in industry'. For better or worse, universities and other state-funded research organizations have become aware of themselves as organizations in need of external support and legitimacy. As Weingart and Guenther rightly note, this means that universities are not interest-free zones. The same can be said for research centres, research groups and even individual scientists. However, this type of organizational dependence on the external world does not, in our eyes, necessarily 'taint' scientific efforts. We know of a great many scientists in all types of organizations who still hail Mertonian norms as a set of values with which to defend and justify their research practices and results. Even within industrially-funded research, whether it takes place in companies or universities, there can be many efforts to comply with ideals of openness, inclusiveness, universalism and organized scepticism.

We do agree that public scrutiny of the form and direction of industrially-funded research is highly necessary and also potentially significant for trust in science. Even if individual industrial researchers might be trying to do the best scientific work they can, they might not be seen to do so by publics sceptical of most types of industrial settings. This means also that heads of research councils need to be careful when boasting of the industrial relevance and economic potential of their activities lest public trust should suffer as a consequence. As with 'science PR', and rather than presenting industrial research as a deviant form of science, we need to maintain a critical, open, and empirically-based perspective on the activities in question.

Fourthly, it is extremely important to consider the specific context and form of interaction. Whilst we recognize the 'layperson' as an ideal type, one has to be very careful not to conflate different publics - some of whom can be very 'specialist' in 
character (as the current attention to 'citizen science' also emphasizes). To this, we would add the argument that public doubt and a reluctance to rely on official information (whether 'scientific' in character or not) do not necessarily lead to irrationality, but can actually be the most sensible and 'informed' way of negotiating everyday life in a complex world. In our opinion, the challenge ahead is to recognize and build on these contextualized understandings rather than creating a schism between 'reliable' scientific knowledge, on the one hand, and 'faith or speculation', on the other.

In general, we find it less than useful to talk about 'a public' and very necessary to think in terms of a host of publics, each with their specific allegiances, values and ways of (dis)trusting authorities. Where we agree wholeheartedly with Weingart and Guenther is that it is high time that we started to think much more thoroughly about the relationships between science, scientific organizations and scientists, and their varying audiences - as well as how these relationships condition and shape trust and trustful collaboration. This demands an understanding of trust - and doubt — as contextual, relational and fluctuating.

In conclusion, we agree that the credibility of communication and trust in communicators are both highly significant for science communication. However, we do not consider that talk of a previous idyll or longing for an un-tainted science which 'transcends political ideologies and/or economic interests' will get us very far forward. Instead, we would argue that Peter Weingart and Lars Guenther's notion of the 'new ecology of communication' should be taken more seriously. From our perspective, one cannot hope to understand the specific relationship between the new social media and issues of public trust unless that evolving ecology is fully recognized in all its richness, dynamism and complexity. Having presented some of the general issues, the next step should be a suitably open but also critical exploration of the changing nature of contemporary science, the diversification of science communication, and the mechanisms of doubt and trust.

Borchelt, R. E. and Nielsen, K. H. (2014). 'Public relations in science: managing the trust portfolio'. In: Routledge Handbook of Public Communication of Science and Technology. Ed. by M. Bucchi and B. Trench. 2nd ed. London and New York: Routledge, pp. 58-69.

Davies, S. R. and Horst, M. (2016). Science Communication: culture, identity and citizenship. London, New York and Shanghai: Palgrave Macmillan. DOI: $10.1057 / 978-1-137-50366-4$.

Horst, M., Davies, S. R. and Irwin, A. (forthcoming). 'Reframing science communication'. In: Handbook of Science and Technology Studies. Ed. by U. Felt, R. Fouché, C. Miller and L. Smith-Doerr. Cambridge, MA, U.S.A. and London, U.K.: MIT Press.

Horst, M. (2013). 'A Field of Expertise, the Organization, or Science Itself? Scientists' Perception of Representing Research in Public Communication'. Science Communication, p. 1075547013487513 . DOI: 10.1177/1075547013487513.

Shapin, S. and Schaffer, S. (1985). Leviathan and the Air-Pump: Hobbes, Boyle, and the experimental life. Princeton, NJ, U.S.A.: Princeton University Press. 
Weingart, P. and Guenther, L. (2016). 'Science communication and the issue of trust'. JCOM 15 (05), C01. URL: http://jcom.sissa.it/archive/15/05/JCOM_1 505_2016_C00/JCOM_1505_2016_C01.

Zimmer, C. (16th May 2016). 'Eske Willerslev Is Rewriting History With DNA'. The New York Times. URL: http://www.nytimes .com/2016/05/17/science/eske-wil lerslev-ancient-dna-scientist.html.

Authors

Alan Irwin is a Professor in the Department of Organization at Copenhagen Business School. His research focuses on science and democracy, scientific governance and the enactment of socio-technical futures. E-mail: ai.ioa@cbs.dk.

Maja Horst is Professor of Science Communication and Head of the Department of Media, Cognition and Communication at the University of Copenhagen. Her research interests include science communication, public engagement with science, and responsible research and innovation. E-mail: horst@hum.ku.dk.

How to cite

Irwin, A. and Horst, M. (2016). 'Communicating trust and trusting science communication — some critical remarks'. JCOM 15 (06), L01. 